\title{
Media Freelancers of the Digital Age: Social, Legal and Ethical Aspects
}

\section{V.F. Oleshko*, and O.S. Mukhina}

Ural Federal University named after the first President of Russia B.N. Yeltsin, Yekaterinburg, Russian Federation

\section{ORCID}

V.F. Oleshko: https://orcid.org/0000-0003-3001-7391

O.S. Mukhina: https://orcid.org/0000-0001-8791-6086

Corresponding Author: V.F.

Oleshko; email:

vladimir.oleshko@urfu.ru

Dates

4 February 2022

Publishing services provided by

Knowledge E

(c) V.F. Oleshko, and O.S.

Mukhina. This article is

distributed under the terms of

the Creative Commons.

Attribution License, which

permits unrestricted use and

redistribution provided that the

original author and source are

credited.

Selection and Peer-review unde the responsibility of the Culture, Personality, Society Conference Committee.
Abstract. The media determine the effectiveness of many current socio-economic and cultural transformations. However, the digital age has created new requirements for the daily work of journalists and other media actors. Freelancing is one of the actively developing trends. According to surveys, media professionals find many advantages to this lifestyle, and the main ones are flexible hours and freedom from the confines of one specific workplace. However, freelance writers often set their own moral and ethical boundaries. The legal and social statuses of media freelancers also remain unclear. The authors analyzed the Accountable Journalism site, which is one of the world's largest databases of journalistic ethics codes. The project contains more than 400 codes, of which 38 codes cover freelancing issues, and another three codes contain norms on the activities of bloggers. In addition, the current Russian legislation on the status of a freelance journalist was used, as well as data from sociological surveys conducted by the authors of this article and other researchers. Unfortunately, the legal and social protection of media freelancers is insufficient. Although the point of view about the inclusion of freelancers in the precariat class is debatable, there are quite enough reasons to distinguish freelancers as a separate social group. However, COVID-19 has given an impetus to the development of freelancing, and the younger 'digital' generations are very loyal to this lifestyle, so it can be predicted that in the near future, the activities of media freelancers will be regulated at all levels: legal, social, and ethical.

Keywords: freelance journalist, code of ethics of a journalist, legal status of a freelancer, media freelance, digital age

\section{Introduction}

The technological changes of the late twentieth century and the first decades of the twenty-first century are accompanied by the transformation of social relations and most spheres of culture. This marked the beginning of a new stage in the study of the influence of these changes on representatives of various societies, as well as on individuals. At the same time, one of the most significant factors determining changes in the social sphere, in the authors' opinion, is the digitalization of media content and the permanent improvement of the ways of collecting, processing, and broadcasting information to the audience. The widespread development of digital communications 
has made freelancing popular as a way to form relationships between the editorial staff of mass media and authors. Modern freelancers work most often online and, as is clear from the word itself, based on the principle of free cooperation, without concluding long-term contracts with any media outlet. In 2020, during the coronavirus pandemic, this became extremely relevant not only for Russia but also for many other countries.

According to the statistics of the Russian Public Opinion Research Center, $11 \%$ of Russians consider themselves freelancers, and another $23 \%$ want to become them. At the same time, this percentage is higher among the younger generation [1]. Journalism is one of the most popular areas of self-realization for freelancers. Traditional media (newspapers, magazines, television) are rapidly losing their audience, and online media need journalists working 24/7. As a result, a fundamentally new model of forming editorial teams becomes widespread. It includes several interrelated structural elements: groups of editors, full-time journalists, "star" authors, and permanent freelancers. Sometimes the practice of active cooperation with citizen journalists is also successfully implemented [2].

In the field of journalism, there are also such types of freelancers as bloggers (working online) and stringers (collaborating with TV channels) [3]. Bloggers are always freelancers, because they publish content on their own websites (if, of course, blogging involves commercial earnings, and is not a hobby). According to a study of the Institute of Public Opinion "Anketolog", $21 \%$ of Russians have their own blog, of which $16 \%$ earn money on it. Predictably, the younger generation is more likely to do this. Its representatives gave a positive assessment of blogging, in contrast to the older respondents, who mostly spoke negatively about this type of activity [4].

In this regard, it is important to identify the social, legal, and ethical features of media freelancing, since independent authors who do not have long-term obligations to any media are, nevertheless, part of the journalistic profession with increased social responsibility. At the same time, both the legal and social statuses of a freelance journalist in modern Russia are not sufficiently regulated. There are also gaps in ethical professional standards. This is dangerous in the situation of globalization and erosion of the boundaries of privacy. In addition, the number of citizen journalists is growing, and they often have no idea about the standards of work in the media. The concept of the professional culture of a journalist is supplemented by the concept of digital culture. In these new conditions, people begin to undergo "processes of changing not only socialization, but also individual identity" [5].

Currently, by introducing the term "self-employed" into the legislation, the Russian authorities admit the existence of freelancers as an independent social group whose 
activities need regulation. At the beginning of 2019 , the self-employed regime was introduced in four regions. It was planned to gradually spread it, but due to the coronavirus pandemic, the regime was extended to the entire territory of Russia earlier (in July 2020). According to the Federal Tax Service of Russia, almost one and a half million self-employed people were registered by December 1, 2020 [6]. However, the actual number of freelancers cannot be accurately calculated (according to various sources, their number can be considered from 12 to 25 million people). The researchers point out that many freelancers do not want to pay taxes, and they also fear a gradual tightening of the regime [7].

The initial advantages of freelancing are attractive to both sides. The mass media does not need to spend money on the workplace, and there is no fixed salary, as practice shows: the author receives a royalty only for the work actually done (some media even practice paying for the number of views of the material on the site). Journalists gain freedom of movement, independent choice of topics for new publications, writing for several media outlets at the same time, and even creating their own brand. According to researchers, freelance journalists most value flexible hours and freedom from a particular workplace [8]. Today, freelancing is not only a way of earning money but also a philosophy of life. This is a popular position of representatives of the creative industries. The media sphere, as one of them, in the form of freelancing receives such significant qualities as the ability to express one's own opinion, independence, and creativity, without the restrictions of editorial policy [3].

However, freelance writers are often not included in the journalistic community. Their acceptance of the moral and ethical values of the profession sometimes causes difficulties. This is evidenced by both Russian and international experience in the formation of the concept of ethical journalism [9]. Besides, freelancers must constantly search for jobs. These are already economic tasks, not just creative ones, and as a result, additional moral dilemmas arise. For example, in a situation of unstable earnings, an individual may agree to fulfill an assignment that in another situation would be considered unacceptable from the point of view of journalistic ethics [10]. This analysis shows that many legal problems of media freelancers also remain unresolved.

\section{Methodology and Methods}

The authors analyzed the Accountable Journalism site, which is one of the world's largest databases of journalistic ethics codes, collected by the Donald W. Reynolds Journalism Institute [11]. The project contains more than 400 codes of individual outlets, 
sectors of the media industry, unions/associations of journalists, press councils, and press clubs. However, only 38 codes more or less cover freelancing issues. Most codes simply combine full-time and freelance journalists, equally addressing them with moral and ethical standards. However, 15 codes have corresponding sections dedicated to media freelancing, and one (Frontline Freelance Register Code of Conduct) regulates only freelance journalism. Another three codes do not specify any features of freelancing, but focus on the activities of bloggers.

The project of the Online News Association also deserves special attention. Its initiators at the conference in 2013 concluded that the boundaries of the journalism profession are blurring, and it "encompasses ever more people, philosophies and technologies". Journalists face the question of self-identification. According to the authors of the project, it is possible to identify a number of fundamental moral and ethical principles that should be accepted by all representatives of the media sphere. However, the creative industry needs flexibility, so everyone is encouraged to create their own codes of ethics based on the templates offered by the site [12]. Boris Lozovsky, a researcher at the Journalism Department of the Ural Federal University, also points to the hybridization of the journalism profession and the crisis of universal values [13]. The website of the Online News Association is both another code of journalistic ethics (consisting of basic principles) and a declaration of a new reality in which everyone creates their own moral and ethical standards.

In addition to studying the ethical component of media freelancing, the authors analyzed the current Russian legislation to solve the problem of determining the legal status of a freelance journalist. Besides, all available open statistics on freelancing and the media sphere were analyzed, preferring the latest data. The results of the authors' own surveys were also used. From 2018 to 2020, essays from journalism students (226 respondents aged 17-35) were collected, and these materials covered issues of digitalization, among others. Also, in October - December 2019, an additional survey of representatives of four "digital generations" about their perception of information and media in general (94 respondents) was carried out. In December 2020, another pilot study was conducted involving five freelance journalists as experts. Representativeness is not sufficient for large-scale conclusions, but the information obtained is valuable due to the accurate sample of respondents.

In addition, one of the authors of this article (O.M.) has a personal seven-year experience of media freelancing and constant communication with colleagues. Therefore, the method of participant observation was also used. 


\section{Results and Discussion}

The results of the conducted analysis show that the existing codes of ethics of journalists do not sufficiently take into account the specifics of freelancing. As the researchers emphasize, the codes are based on general ethical principles, but their real implementation depends on the level of morals in society [14]. Freelance journalism is a phenomenon of the current reality, but its regulation by both Russian legislation and codes of ethics is not enough. Therefore, it is necessary to study the world's experience.

Most of the norms of the codes of journalistic ethics are known to all journalists from democratic countries: freedom of speech, verification of information, use of multiple sources, protection of sources, respect for each person, prohibition of plagiarism and manipulation of information, etc. Thus, most of the standards are based on the longestablished principles of traditional media. The codes of ethics of individual media outlets may seem more unusual. The norms listed above (formulated mainly by the codes of ethics of countries or public organizations) are rather idealistic and focus on moral responsibility to society and the audience, while the codes of individual outlets force authors to take care of the reputation and income of this particular media, its owners and editors. For example, freelance authors of many media outlets are prohibited from collaborating with competing media, and even such seemingly personal activities as writing a personal blog or creating a book are subject to approval by the editor, because the audience may associate a journalist's personal publications with the media, and this may affect its reputation. Authors should also offer any ideas or materials to this media first, and only then to others. However, they should present themselves on behalf of the media only by performing its task, and clearly indicate their status as a freelancer.

Having highlighted the responsibilities of journalists, now let us focus on the need to protect them. As noted above, the Russian authorities are currently trying to formally legalize the work of freelancers with the help of a new self-employed regime. However, according to statistics, only a small percentage of them used this opportunity. The old ways of forming relationships between editors and freelancers are more popular: an employment contract (traditional fixed schedule, salary, sick leave and vacation, just work is carried out online), a civil contract (only royalties for the work actually done), or registration of the status of an individual entrepreneur or a limited liability company (similar to the previous option, but paying taxes becomes the responsibility of a freelancer). Innovations in the form of the self-employed regime resemble registration as an individual entrepreneur, but with lower taxes and without the right to hire employees [7]. 
If the activity of a freelancer does not fall under any of these options, then it can be recognized as illegal entrepreneurship with criminal liability. However, in the field of journalism, this is hardly possible: such negative consequences appear when providing services to individuals, and freelance writers usually cooperate with the media. Even in the absence of a written contract, it is considered concluded orally or by exchanging documents. However, some freelancers sell the authorship of the materials. In such cases, the contract is sometimes concluded between two individuals and may entail liability.

The social protection of freelance journalists is also insufficient. Separated from the staff teams, they are not members of unions of individual outlets and very rarely join other journalistic organizations. In modern sociology, the concept of "precariat" appeared, formed as a merger of the Latin word "precarium" (precarious) and the term "proletariat", as a definition of the exploited class [15]. The precariat class, in addition to freelancers, includes the unemployed, downshifters, migrants, retirees, etc.

However, freelancers usually oppose themselves to the proletariat (mainly the office "proletariat" of the modern type). According to the pilot expert survey of freelance journalists, when asked to choose any type of employment (with the same conditions for payment, work schedule, and workload), the majority of respondents said that they preferred completely remote work, and only one spoke in favor of partial freelancing with rare office visits. No one wanted to return to full-time office work. Therefore, it is premature to talk about the miserable life of freelancers as unprotected and exploited. However, in the authors' opinion, the main question is who made the decision to switch individuals to freelance. If the head of the enterprise forced employees to leave the company's staff, then this is the precariat. If it was a free decision of the specialists themselves, then they are freelancers. For example, according to statistics from European researchers, in the northern European countries, the majority of freelancers, about $80 \%$, have chosen this status on their own initiative, while in Romania, Portugal, and Croatia, most remote employees adopted it out of necessity [16]. In Russian science, both opinions exist: according to the first, freelancing is the result of the crisis and unemployment [17], according to the second, it is the search for freedom [2].

Anyway, there are quite serious reasons for separating freelancers into a new social class. First of all, a class is determined through its position in the regulated market [18], its role in the organization of labor, and its relation to the means of production. In the new economic environment, freelancers are a group with unique characteristics that distinguish them from other social strata. Sociologists point out that it is necessary to create a classification of the working-age population, taking into account 
new professions and social groups, because this new, continuously increasing stratum in the social structure is characterized by an unclear status. Based on the existing classifications, freelancers can belong to several classes at the same time according to different criteria. Therefore, the researchers propose new approaches that define the boundaries of the freelancer class from a sociological point of view [19] and note that the social community of freelancers differs from other communities in status, value, and behavioral characteristics [20].

The authors' surveys of different generations, including the issues of media perception and digitalization, show the high importance of freedom for younger generations. Therefore, it is natural that young people (on average 17-35 years old) positively assess such phenomena of modern reality as blogging, citizen journalism, and media freelancing in general.

\section{Conclusions}

The COVID-19 pandemic transformed economic relations and identified the role of the media as significant in their implementation in various areas of human life. As for the media sphere, many professional journalists were transferred to freelance work. Although even in the pre-digital era, quite a large number of them did not sit in editorial offices, visiting them only for direct communication with top management and informal communication with colleagues. The Internet has helped to actively develop various forms of freelance journalism, while the coronavirus has simply increased the percentage of remote authors in the model of forming a team of modern media.

However, Russian media freelancing, of course, has not yet been sufficiently studied. In the Soviet Union, it was impossible not to be on the staff, otherwise, the individual was called a parasite and a loafer [21]. Although freelance journalists (worker-peasant correspondents) existed (there were about 5 million of them in the 1960s [22]), it was a completely different format of employment, which cannot be fully called freelancing, because these authors had a permanent job, just not in the media sphere.

Therefore, the experience of Western countries with the longer practice of freelancing can be useful. European unions of journalists, including freelancers, are very active and achieve significant results. They protect the rights of independent journalists. The activities of these associations are aimed at collective bargaining, as well as the uniting and training of freelancers, including on security issues [23]. They do not just add freelance features to their codes of ethics. Journalistic organizations and unions conduct collective negotiations, help authors get good pay conditions, and fight 
against contracts that exploit freelancers. Western researchers point out successful cases of collective opposition of freelance journalists when the media tried to enforce unfavorable conditions [24]. One has to admit that Russian freelance journalists are much more divided and usually do not have such a collective force.

The world has switched to the digital space, but has not yet edited either the legislative or ethical norms of the media sphere. However, the media are the most essential actors in the formation of ideological attitudes, as well as cross-cultural and intergenerational relations. Some countries and organizations are quick and flexible in responding to social and technological transformations. However, most have yet to make changes to the standards of media activity. It is important to do this as quickly as possible, taking into account the increased social significance of the profession of a journalist. In general, the media freelance industry is actively developing, and the younger, "digital" generation is very loyal and positive about freelance work, so one can predict its further spread. This will inevitably lead to widespread regulation at both the legislative and ethical levels. Currently, the world is probably witnessing the last stage of almost complete independence of freelance journalists.

\section{Acknowledgments}

The reported study was funded by RSF according to the research project No. 19-1800264 entitled "Digitalisation of communicative-cultural memory and problems of its intergenerational transmission."

\section{References}

[1] WCIOM. The Russians loved freelancing. WCIOM News [Internet]. 2020 March 4 [cited 2021.02.03]. Available from: https://wciom.ru/analytical-reviews/analiticheskiiobzor/rossiyane-polyubili-frilans

[2] Kapustina AA. Freelance journalism in the 21st Century: Working conditions and evaluations. The Age of Information. 2019;7(1):119-125.

[3] Shcherbal SS, Stepanova ID. Journalism, multimedia: Information and socio-cultural potential. Kasyanov VV, editor. Krasnodar: Publishing House of the Kuban State University; 2020.

[4] Anketolog. Bloggers or media: Who is trusted more? Anketolog [Internet]; 2020 Jun 15. Available from: https://iom.anketolog.ru/2020/06/15/blogery 
[5] Kokhanova LA, Alekseeva TS, Chereshneva YE. Opportunities and threats of the digital society. Sokolova AV, Frolova AA, editors. Yaroslavl: Digital Printing House; 2020. Digital culture as a competitive advantage for future journalists.

[6] Ageeva O. The accounting chamber switched to selfemployment. RBC [Internet]; 2020 Dec 10. Available from: https://www.rbc.ru/newspaper/2020/12/10/5fdOb2179a79474c2b46121c

[7] Azarenko VE. Problem of implementation of the institute of self-employed citizens in the legislation of the Russian Federation. Meridian. 2020;7(41):210-212.

[8] Kapustina AA. Modern media environment: Traditions, current practices and trends. Malyshev AA, editor. Saint Petersburg: Publishing House of St. Petersburg State University; 2019.

[9] Kuzmich SV. Philology, linguistics, journalism: Current issues and modern aspects. Gulyaev GY, editor. Penza: Nauka I Obrazovanie; 2020.

[10] Mathisen BR. Ethical boundaries among freelance journalists. Journalism Practice. 2019;13(6):639-656.

[11] Accountable journalism. Codes of ethics. Accountable journalism [Internet]. Missouri, US: Reynolds Journalism Institute; 2021.01.25 [cited 2021.01.25]. Available from: https://accountablejournalism.org/ethics-codes

[12] ONA Ethics - ONA Build Your Own Ethics Code [Internet]. Burlington, USA: Online News Association; c2021. A customized ethics code for every organization; ?2021 [cited 2021.01.25]. Available from: https://ethics.journalists.org/about/

[13] Lozovsky BN. Professional culture of a journalist in the context of media transformations: Monograph. Myasnikova MA, editor. Ekaterinburg: Publishing House of the Ural Federal University; 2020.

[14] Chebotarev OY. Journalistic ethics in digital environment: Adaptation of journalistic codes to new media. Social and Humanitarian Knowledge. 2020;4:341-349.

[15] Toshchenko ZT, editor. Precariat: The emergence of a new class (Collective monograph). Moscow: Center for Social Forecasting and Marketing; 2020.

[16] Guyot C. Europe's silent shift to self-employment. Euractiv; 2018 Jul 3. Available from: https://www.euractiv.com/section/economy-jobs/news/a-silent-shift-to-selfemployment-in-europe/

[17] Emirova GA. Social and political preconditions for the development of the market of freelancing in the face of rising unemployment in the industry media. Fundamental Research. 2015;11(6):1277-1281.

[18] Anikin VA. Social classes of the new Russia: Unequal and different. Sociological Research. 2020;2:31-42. 
[19] Bondareva IY. Sociologist 2.0: Transformation of the profession. Kuleshova AV, editor. Moscow: Russian Public Opinion Research Center; 2018.

[20] Akhmetshina ER, Klyueva TV, Poletaeva OV. Specifics of labor practices and social status of freelancers in the Russian regions. Labour and Social Relations. 2016;2:93105.

[21] Peshkova VV. Parasitism: The experience of the past and the problem of the present. Synergy of Sciences. 2017;15:649-658.

[22] Sarma OV, Antonova VI. Problems of media communication in the context of sociopolitical challenges of the period of SMIP liberalization. Culture in the Focus of Scientific Paradigms. 2020;10-11:353-356.

[23] European Federation of Journalists [Internet]. Brussels, Belgium: European Federation of Journalists; c2021. Freelance; c2021 [cited 2021.01.25]. Available from: https://europeanjournalists.org/policy/freelance/

[24] Salamon E. E-lancer resistance. Digital Journalism. 2016;4(8):980-1000. 